\title{
EVOLUTIONARY CHANGE IN TESTES TISSUE COMPOSITION AMONG EXPERIMENTAL POPULATIONS OF HOUSE MICE
}

\begin{tabular}{|c|c|}
\hline Journal: & Evolution \\
\hline Manuscript ID: & Draft \\
\hline Manuscript Type: & Brief Communication \\
\hline Date Submitted by the Author: & $n / a$ \\
\hline Complete List of Authors: & $\begin{array}{l}\text { Firman, Renee; University of Western Australia, Animal Biology (M092); } \\
\text { Garcia-Gonzalez, Francisco; University of Western Australia, Centre for } \\
\text { Evolutionary Biology } \\
\text { Tyler, Evan; University of Western Australia, Centre for Evolutionary } \\
\text { Biology } \\
\text { Wheeler, Samantha; University of Western Australia, Centre for } \\
\text { Evolutionary Biology } \\
\text { Yamin, Zayaputeri; University of Western Australia, Centre for Evolutionary } \\
\text { Biology } \\
\text { Yuan, Michael; University of Western Australia, Centre for Evolutionary } \\
\text { Biology } \\
\text { Simmons, Leigh; University of Western Australia, Centre for Evolutionary } \\
\text { Biology; University of Western Australia, School of Animal Biology (M092) }\end{array}$ \\
\hline Keywords: & Mating Systems, Selection - Experimental, Selection - Sexual \\
\hline
\end{tabular}


3 EVOLUTIONARY CHANGE IN TESTES TISSUE

4 COMPOSITION AMONG EXPERIMENTAL

5 POPULATIONS OF HOUSE MICE

6

7 Renée C. Firman ${ }^{1,2}$, Francisco Garcia-Gonzalez ${ }^{1,3}$, Evan Thyer ${ }^{1}$,

8 Samantha Wheeler ${ }^{1}$, Zayaputeri Yamin ${ }^{1}$, Michael Yuan ${ }^{1}$ and

$9 \quad$ Leigh W. Simmons $^{1}$

$11{ }^{1}$ Centre for Evolutionary Biology, School of Animal Biology (M092),

12 University of Western Australia, Nedlands 6009, Australia

${ }^{2}$ E-mail: renee.firman@uwa.edu.au

$14{ }^{3}$ Estacion Biologica de Doñana-CSIC, 41092, Sevilla, España

21 Running head: Evolutionary change in the testes in mice 
23 Theory assumes that postcopulatory sexual selection favours increased investment in

24 testes size because greater numbers of sperm within the ejaculate increase the chance

25 of success in sperm competition, and larger testes are able to produce more sperm.

26 However, changes in the organization of the testes tissue may also affect sperm

27 production rates. Indeed, recent comparative analyses suggest that sperm competition

28 selects for greater proportions of sperm-producing tissue within the testes. Here, we

29 explicitly test this hypothesis using the powerful technique of experimental evolution.

30 We allowed house mice (Mus domesticus) to evolve via monogamy or polygamy in

31 six replicate populations across 24 generations. We then used histology and image

32 analysis to quantify the proportion of sperm-producing tissue (seminiferous tubules)

33 within the testes of males. Our results show that males that had evolved with sperm

34 competition had testes with a higher proportion of seminiferous tubules compared

35 with males that had evolved under monogamy. Previously, it had been shown that

36 males from the polygamous populations produced greater numbers of sperm in the

37 absence of changes in testes size. We thus provide unequivocal evidence that sperm

38 competition selects for an increase in the density of sperm-producing tissue, and

39 consequently increased testes efficiency.

40

41

42

43

44

45

46

47 
48 Parker's game theoretic models of ejaculate evolution assume that sperm competition

49 conforms to a raffle, with the relative number of sperm from each competitor being

50 the primary determinant of paternity success (Parker and Pizzari 2010). In support of

51 sperm competition theory, evolutionary and reproductive biologists focusing on in

52 vivo sperm competition dynamics have shown that males that produce ejaculates with

53 high numbers of sperm typically have a fertilization advantage over their rival/s (e.g.

54 domestic species, Beatty 1957; Martin et al. 1974; wild species, Gage and Morrow

55 2003; Boschetto et al. 2011; Firman and Simmons 2011). Thus, when male fitness is

56 contingent on the number of sperm within the ejaculate, it is likely that postcopulatory

57 selection will target the organ responsible for sperm production, and evolutionary

58 change will ensue (Parker 1970).

59 A positive correlation between testes size and the level of sperm competition, as

60 determined by variation in mating system, the frequency of female remating,

61 differences in population sex ratio, etc, has been observed. A multitude of studies

62 have implicated intense selection via sperm competition as favoring the evolution of

63 larger testes both within (Ribble and Millar 1992; Brown and Brown 2003; Long and

64 Montgomerie 2005; Firman and Simmons 2008; Dzminiski et al. 2009) and between

65 species (e.g. primates, Harcourt et al. 1981; butterflies, Gage 1994; bats, Hosken

66 1997; frogs, Byrne et al. 2002; birds, Pitcher et al. 2005; scorpions, Vrech et al. 2014).

67 To date however, the most convincing evidence for the role of sperm competition in

68 testes size evolution comes from investigations that have maintained evolving

69 laboratory populations, and found reductions in testes mass with the removal of sperm

70 competition (Hosken and Ward 2001; Pitnick et al. 2001; Simmons and Garcia-

71 Gonzalez 2008). This significant body of literature has resulted in testes size (relative

72 to body size) being routinely used as an indirect measure of sperm competition risk. 
73 Unfortunately, the underlying critical assumption that testes size accurately reflects

74 sperm production rate has largely been overlooked (discussed by Schärer et al. 2004).

75 Certainly, variation in testis size alone may not necessarily reflect differences in

76 sperm production rate, and evidence has emerged to support the idea that sperm

77 competition selects to maximise testicular efficiency beyond changes in testes size

78 (reviewed in Ramm and Schärer 2014).

79 The testis consists of spermatogenic tissue, which includes germ cells and

80 somatic cells (called Sertoli cells in mammals), and non-spermatogenic tissue with

81 somatic cells only (e.g. blood vessels and Leydig cells). In higher vertebrates the germ

82 cells are located within the long and convoluted seminiferous tubules (Gier and

83 Marion 1970; Roosen-Runge 1977; Wistuba et al. 2007). During the process of

84 spermatogenesis the germ cells develop from spermatogonia into spermatocytes, then

85 to spermatids, and finally spermatozoa (Roosen-Runge 1977; Wistuba et al. 2007).

86 Spermatozoa are released from the nourishing Sertoli cells to enter the lumen of the

87 seminiferous tubule before being passed into the efferent ducts and transported to the

88 epididymis for maturation. The interstitial tissue that surrounds the seminiferous

89 tubules supplies blood to the testis and produces endocrine signals via the Leydig

90 cells (Wistuba et al. 2007).

91 It has long been known that seasonal variation in the amount of sperm-

92 producing tissue versus non sperm-producing tissue occurs in many different taxa

93 (e.g. Mayhew and Wright 1970; Goldberg and Parker 1975; Hochereau-de Reviers

94 and Lincoln 1978; Fuentes et al. 1991). Since Harcourt et al. (1981) first indicated

95 that sperm competition has the potential to select for increased sperm production rates

96 via alternations in the spatial organization of the testes, a number of comparative

97 studies have explored the association between the proportion of sperm-producing 
tissue within the testes and postcopulatory sexual selection (Wistuba et al. 2003;

99 Lüpold et al. 2009; Rowe and Pruett-Jones 2011; Montoto et al. 2012). Interspecies

100

101

106

107

108 comparisons have provided general evolutionary patterns, but fail to demonstrate cause and effect. In their review on the evolutionary ecology of testicular function, Ramm and Schärer (2014) called for researchers to explore directly the consequences of sperm competition for testes machinery by using the powerful technique of experimental evolution. Here we provide the first account. We quantified the amount of sperm-producing and interstitial tissue from images of histological preparations of the testes of male house mice (Mus domesticus) from six replicate populations that had been evolving under a monogamous or polygamous mating regime for 24 generations. Our analyses revealed that the testes of males that had evolved with sperm competition had greater proportions of seminiferous tubules compared to males that had evolved via monogamy. Previously, it had been shown that males from the polygamous populations produced ejaculates with elevated sperm numbers in the absence of changes in testes size (Firman and Simmons 2010). Thus, our result here suggests that sperm competition acts directly on the spatial organisation of the testes, which is likely to select for enhanced efficiency and the production of more sperm.

\section{Materials and Methods}

\section{EXPERIMENTAL ANIMALS}

House mice are actively polygamous in nature, with both males and females copulating with multiple mates (Dean et al. 2006; Firman and Simmons 2008). However, laboratory strains of house mice are typically maintained under an enforced monogamous mating regime. The Uwa:MMD colony of wild-derived mice was established in 1997 at the Animal Resources Centre (ARC) (Murdoch, Western 
123 Australia) with 90 breeding pairs sourced from six wild, Australian Mus domesticus

124 populations. From 1997 to 2002 the colony was maintained as an outbred population

125 under the Poiley outbreeding system (Poiley 1960), after which the outbreeding

126 regime changed to a dedicated program based on the coefficient of inbreeding

127 (Firman and Simmons 2010). Consequently, the Uwa:MMD colony was maintained

128 under a strict monogamous mating regime for approximately 30 generations prior to

129 the establishment of the selection lines. Male/female pairs $(n=60)$ reproduced to

130 establish a base population from which our selection lines were derived, for which we

131 referred to the ARC colony pedigree to ensure that close relatives did not breed.

132 At the University of Western Australia the animals were maintained in a

133 constant temperature room under identical conditions $\left(24^{\circ} \mathrm{C}\right.$; reversed $14: 10$ hour

134 light-dark cycle), and food and water was provided ad libitum. We established four

135 monogamous and four polygamous lines with 18 males and 18 females in each.

136 Subsequently, 18 males and 18 females contributed to each generation. In the

137 monogamous lines, almost all selection on adult fitness was eliminated by ensuring

138 that every male and female pair contributed one son and one daughter to the next

139 generation (Shabalina et al. 1997). Although greatly relaxed, selection may not have

140 been completely eliminated because sometimes a pair did not mate or produce

141 offspring. In the polygamous lines, adult females had equal fitness (two offspring),

142 and adult males had equal mating success but not equal fertilisation success due to

143 sperm competition and/or cryptic female choice. Four polygamous lines were

144 established with 18 females and 18 males, but potentially $<18$ sires. In the

145 polygamous lines, the same three males mated with the same three females. Thus,

146 males in the polygamous lines competed for fertilizations, and the number of males

147 who contributed to successive generations was determined by the relative paternity 
148 success of each male. This mating design ensured that the effective population sizes

149 of the monogamous lines were potentially greater than the polygamous lines at each

150 generation. Therefore, any observed fitness benefits associated with sperm

151 competition would be conservative, as the polygamous lines would be expected to

152 have higher inbreeding coefficients than the monogamous lines (documented at

153 generation 12; Firman \& Simmons 2011). As with the monogamous lines, one male

154 and one female were selected at random from each polygamous line litter and used to

155 produce the next generation. Consequently, while postcopulatory sexual selection on

156 males was reinstated in the polygamous lines, natural selection and precopulatory

157 sexual selection remained absent in both treatments.

158 Anatomical measurements and sperm quality assays initially performed after

159 eight generations of experimental evolution revealed that males had diverged in sperm

160 number without changes in testes size (Firman and Simmons 2010; Table S1 in the

161 online supplementary material). Males from the polygamous lines produced more

162 sperm, had a greater proportion of motile sperm, and sperm with greater swimming

163 velocities than males from the monogamous lines, as would be expected following

164 selection via sperm competition (Firman and Simmons 2010). Further, testes size

165 among males from the different selection regimes had not changed following 16

166 (Firman et al. 2011) or 18 (Table S1; Table S2) generations of selection. Males from

167 the $24^{\text {th }}$ generation were used here to assess evolutionary change in the spatial

168 organisation of the testes. Due to time and resource restrictions, we were limited to

169 using a randomly selected sample of three monogamous $(\mathrm{n}=10 \mathrm{males} / \mathrm{line})$ and three

170 polygamous $(\mathrm{n}=10$ males/line $)$ selection lines.

171 Variation in the social environment can induce plasticity in sperm production in

172 house mice (Ramm and Stockley 2009; Firman et al. 2013). Consequently, the 
173 animals used in this experiment were reared under identical conditions. Thus, after

174 being weaned from their mother at three weeks of age, each male was housed in an 175 individual cage until they reached sexual maturity (12 weeks of age). To ensure that 176 males acquired the appropriate olfactory cues during their sexual development they

177 were placed within close proximity to cages housing females. All males were virgins 178 at the time of sacrifice.

179

180

181

182

183

184

185

186

187

188

189

190

191

192

194

195

\section{TESTES HISTOLOGY AND IMAGE ANALYSIS}

Males were sacrificed via lethal injection and stored at $-20^{\circ} \mathrm{C}$. Prior to dissection, the bodies were defrosted and weighed. A single testis from each male was chosen at random and fixed in 10\% buffered formal saline. Each testis was dehydrated through a series of graded ethanol baths, chloroform baths, and paraffin, and then embedded in paraffin wax. The specimens were sectioned through the midline, and centre sections of the testis were mounted on slides. The slides were stained with Gill's haematoxylin and Eosin and viewed under a BX50 (Olympus) light microscope $(\times 10$ objective $)$.

Five different images per testis were captured using an Olympus DP72 camera attached to the microscope. Testis tissue covered the entire area in each image (Fig. 2).

Each image was visualized using the image analysis software ImageJ. We quantified the proportion of sperm-producing tissue within each image. Thus, we measured and recorded the area of each seminiferous tubule (including the tubule lumen) within each image (see Fig. S1 in the online supplementary material). We then calculated the proportion of sperm-producing tissue per image: sum[seminiferous tubule area]/total image area. The 300 images were distributed randomly among four different investigators, and each investigator was blind to the treatment from which 
198 the images were sourced.

199

200

\section{STATISTICAL ANALYSES}

201 To confirm that investigator bias did not influence our measurements and results, a set

202 of eight images were measured by the four investigators, which allowed us to perform

203 a repeatability analysis on those measurements. A Levene's Test was applied to test

204 the equality of variances in the proportion of sperm-producing tissue among the

205 replicate lines (SciStat Calc 2013). We used JMP statistical software to perform a

206 nested analysis of variance (ANOVA) with replicate lines nested within selection

207 treatments (random effect) to account for non-independence of replicate lines. Effect

208 size analysis was calculated using the library "compute.es" in $R$. All means are

209 presented \pm 1 SE.

\section{Results}

\section{SPERM NUMBER AND TESTES SIZE MEASUREMENTS}

213 The repeatability analysis revealed that there was no measurement bias among the

214 investigators. There was significantly more variation between images than within

215 images $\left(F_{7,24}=17.171, P<0.001 ; R=0.500\right.$, calculated following Becker 1984).

216 We calculated the mean proportion of sperm-producing tissue for each male. A

217 Levene's Test revealed that the variances in the mean proportion of sperm-producing

218 tissue were equal among the replicate lines $(n=6, W=0.778, P=0.570)$. Thus, we

219 looked for an effect of selection history among males from the different experimental

220 populations.

A nested ANOVA revealed significant variation in the proportion of total tubule

222 area among males from the polygamous and monogamous selection lines (Table 1). 
223 The mean difference in the proportion of sperm-producing tissue between treatments

224 was $4.6 \%$. Males from the polygamous lines had testes with greater proportions of

225 sperm-producing tissue $(n=3,0.747 \pm 0.008)$ compared with males from the

226 monogamous lines $(n=3,0.701 \pm 0.009)$ (Fig. 1; Fig. 2). We calculated a

227 standardized mean difference effect size (Cohen's $d$ ) and the associated 95\%

228 confidence intervals (CIs) to gauge the magnitude of the observed effect of selection

229 history $(d=4.66[0.29,9.03])$ on the proportion of total tubule area. The effect size is

230 large, and the $95 \%$ CIs give us confidence in rejecting the hypothesis that selection

231 history had no effect on tubule area.

232

233 Discussion

234 Testes size evolution via postcopulatory sexual selection is well evidenced

235 (Gomendio et al. 1998; Simmons 2001; Birkhead et al. 2009). Both inter- and intra-

236 species comparisons have shown that sperm competition typically favours an increase

237 in the amount of spermatogenetic tissue, and thus larger testes (e.g. Gage 1994;

238 Hosken 1997; Byrne et al. 2002; Firman and Simmons 2008; Dzminiski et al. 2009).

239 However, in addition to gross testes size, the relative proportion of sperm-producing

240 tissue within the testes could also be an important factor determining spermatogenic

241 investment (Ramm and Schärer 2014). Certainly, the capacity of the mammalian

242 testes to produce sperm varies considerably across taxa; among six rodent species the

243 proportion of sperm-producing tissue within the testes has been shown to range from

$24433 \%$ to $90 \%$ (Russell et al. 1990). Within Mus, the level of sperm competition (as

245 estimated by relative testes size) correlates with both the number of sperm produced

246 (Montoto et al. 2011) and the proportion of seminiferous tubules within the testes

247 (Montoto et al. 2012). Similar evolutionary associations between the intensity of 
248 sperm competition and testes tissue organization have been observed in comparative

249 studies of two groups of birds, the New World blackbirds (Icteridae) and the

250 Australian passarines (Maluridae) (Lüpold et al. 2009; Rowe and Pruett-Jones 2011).

251 Here, we show that male house mice from experimental populations evolving with

252 sperm competition have testes with greater proportions of sperm-producing tissue

253 compared to the testes of males from populations maintained under enforced

254 monogamy.

255 An increase in the proportion of spermatogenic tissue in the testes of males from

256 the polygamous lines could be ascribed to selection acting on standing genetic

257 variation in testes tissue organisation. Alternatively, as we reinstated sperm

258 competition in a source population that had experienced a long history of monogamy,

259 in which deleterious mutations might have accumulated, our result could be explained

260 by sperm competition successfully purging mutations that influenced testes

261 phenotype. While theory predicts that sexual selection on males can substantially

262 reduce the accumulation of mildly deleterious mutations (McLearn and Manning

263 1985; Whitlock and Agrawal 2009), experimental evidence among different

264 invertebrate species is contradictory (e.g. Radwan 2004; Hollis et al. 2009; Arbuthnott

265 and Rundle 2012; Almbro and Simmons 2014). To date, there have been no direct

266 tests of whether mutation accumulation influences testes tissue composition, however

267 it is interesting to note that a recent study of the dung beetle Onthophagus taurus

268 found that sexual selection was ineffective in removing deleterious mutations that

269 reduced testes mass (Almbro and Simmons 2014).

270 Deleterious recessive mutations can be exposed under conditions of inbreeding

271 (Charlesworth and Charlesworth 1999). Consequently, if individuals from our

272 monogamous selection lines were 'carrying' high mutation loads they might be 
273 expected to experience greater fitness consequences from reproducing with relatives

274 compared with individuals from the polygamous lines. Within-line experimental

275 matings performed after 16 generations of selection revealed that full-sibling parental

276 pairs and unrelated parental pairs had equivalent fitness (Firman et al. 2011). Further,

277 the resulting 'inbred' polygamous and 'inbred' monogamous male offspring had, on

278 average, comparable testes sizes and sperm numbers (Firman et al. 2011). Thus,

279 although we are unable to eliminate conclusively that sperm competition purged

280 deleterious alleles that influenced testes phenotype and suppressed testes function,

281 available data suggests that this was not the case. Regardless, we have provided

282 compelling evidence that sperm competition selects for enhanced levels of sperm-

283 producing tissue, either by selecting against males with high mutation loads, or by

284 acting on standing genetic variation. Certainly, these two mechanisms are not

285 mutually exclusive and are likely to co-occur in both experimental and natural

286 populations.

287 A series of previous investigations performed using these lineages of house

288 mice had revealed that males from populations evolving via sperm competition

289 produced more sperm compared with males from populations evolving under

290 monogamy, but that changes in sperm production were not associated with changes in

291 testes size (Firman and Simmons 2010; Firman et al. 2011). Moreover, the increase in

292 sperm production resulted in enhanced success in sperm competition (Firman and

293 Simmons 2011). We do not have testes size data from males from the $24^{\text {th }}$ generation,

294 however testes size had not diverged after eight (Firman and Simmons 2010), 16

295 (Firman et al. 2011) or 18 generations of selection. Thus, it is likely the increase in

296 sperm production among males from the polygamous lines is attributable to an

297 increase in the proportion of sperm-producing tissue, which was documented here. 
Sperm production is also influenced by the efficiency of the sperm-producing

299 tissue, for example the rate at which individual sperm can be manufactured. In mammals, the duration of spermatogenesis is defined as the 'seminiferous epithelium

301 cycle length' (SECL), describing one complete series of cell associations that occurs 302 in the seminiferous epithelium (Clermont 1972). Across species, variation in SECL 303 has been shown to correlate negatively with relative testes size, supporting the idea 304 that sperm competition selects for a faster rate of spermatogenesis (Pierce and Breed 305 2001; Paraponov et al. 2008; Ramm and Stockley 2010). In addition to evolutionary 306 responses, variation in the speed of spermatogenesis might also account for the 307 adaptive plasticity in sperm production that has been observed in response to local 308 sperm competition conditions (delBarco-Trillo and Ferkin 2004; Ramm and Stockley 309 2009; Firman et al. 2013). Our findings on house mice have important implications

310 for the general assumption that larger testes confer greater rates of sperm production, 311 and emphasise the need for explorations beyond a simple measure of testes size and 312 into testes tissue organisation and function (Ramm and Schärer 2014).

313 As almost all male sex hormone production occurs in the testes interstitium

314 (Stocco and McPhaul 2006), we contend that an increase in the proportion of 315 seminiferous tubules and a reduction in the amount of interstitial tissue could have 316 important implications for precopulatory sexual selection. Testosterone, which is 317 produced by the Leydig cells, plays a critical role in the promotion of secondary 318 sexual characters (Dufau 1996). For example, testosterone-dependent urine scent319 marking behaviour in male house mice is indicative of dominance status and territory 320 defense (Desjardins et al. 1973; Hurst 1990), and is assessed by females to gauge the 321 quality of potential mates (Wolff 1985, Penn and Potts 1998). Variation in 322 testosterone levels can lead to changes in the major urinary proteins that mediate the 
323 release of pheromones (Harvey et al. 1989). Therefore, a reduction in testes interstitial

324 tissue, and consequently a reduction in the density of Leydig cells, could result in a

325 reduction in testosterone production and influence the quality or frequency of scent-

326 marks produced by males. A recent study has revealed that sexually receptive females

327 spent more time associating with males from the monogamous populations compared

328 to males from the polygamous populations, suggesting that these males have a

329 precopulatory advantage which could be attributable to an intrinsic quality associated

330 with the scents that they produce (Firman 2014). The divergence in testes tissue

331 composition among males evolving with and without sperm competition reported here

332 certainly warrants further research into evolutionary trade-offs between pre- and

333 postcopulatory sexually selected traits.

334 In summary, we have documented divergence in testes tissue composition

335 among house mice from populations that had evolved under a polygamous or

336 monogamous mating regime for 24 generations. Our statistical analysis revealed that

337 males that had evolved with sperm competition had testes with a significantly greater

338 proportion of seminiferous tubules compared with males that had evolved under

339 enforced monogamy. Our finding accounts for the previously reported divergence in

340 sperm number and sperm competitiveness that had been observed in the absence of

341 evolutionary changes in testes size (Firman and Simmons 2010; Firman and Simmons

342 2011). This study has important implications for the general, mostly untested

343 assumption that testes size is a strong predictor of sperm production, and emphasizes

344 the need for future research to explore the evolutionary implications of sperm

345 competition for testicular efficiency. 


\section{ACKNOWLEDGEMENTS}

349 We thank Tom Stewart for assistance with histology, and Freddy Simmons and

350 Shresta Lobind for animal husbandry. This research was funded by the Australian

351 Research Council (RCF, FG-G, LWS). FG-G was also supported by the Spanish

352 Ministry of Economy through the Ramon y Cajal program and grant (cofunded by the

353 European Regional Development Fund) CGL2012-34685. The research was approved

354 by the UWA Animal Ethics Committee (07/100/607).

355

356 LITERATURE CITED

357 Almbro, M., and L. W. Simmons. 2014. Sexual selection can remove an

358 experimentally induced mutation load. Evolution 68:295-300.

359

360 Arbuthnott, D., and H. D. Rundle. 2012. Sexual selection is ineffectual or inhibits the

361 purging of deleterious mutations in Drosophila melanogaster. Evolution 66:2127-

$362 \quad 2137$.

363

364 Beatty, R. A. 1957. A pilot experiment with heterospermic insemination in the rabbit.

365 J. Genet. 55:325.

366

367 Becker, W. A. 1984. Manual of quantitative genetics. Pullman, Washington.

368

369 Birkhead, T. R., Hosken, D. J., and Pitnick, S. 2009. Sperm biology. An evolutionary

370 perspective. Academic Press, Burlington MA. 
372 Boschetto, C., C. Gasparini, and A. Pilastro. 2011. Sperm number and velocity affect

373 sperm competition success in the guppy (Poecilia reticulata). Behav. Ecol. Sociobiol. $374 \quad 65: 813-821$.

375

376 Brown, C.R., and M. B. Brown. 2003. Testis size increases with colony size in cliff 377 swallows. Behav. Ecol. 14: 569-575.

378

379 Byrne, P. G., J. D. Roberts and L. W. Simmons. 2002. Sperm competition selects for 380 increased testes mass in Australian frogs. J. Evol. Biol. 15:347-355.

381

382 Lee, C. 1976. Agonistic behavior, sexual attraction, and olfaction in mice. Pp. 161383180 in R. Doty, ed. Mammalian Olfaction, Reproductive Processes and Behaviour. 384 Academic Press, London.

385

386 Clermont, Y. 1972. Kinetics of spermatogenesis in mammals: seminiferous 387 epithelium cycle and spermatogonial renewal. Physiol. Rev. 52:198-236.

388

389 Dean, M. D., K. G. Ardlie, and M. W. Nachman. 2006. The frequency of multiple 390 paternity suggests that sperm competition is common in house mice (Mus 391 domesticus). Mol. Ecol. 15:4141-4151.

393 delBarco-Trillo, J., and M. H. Ferkin. 2004. Male mammals respond to a risk of 394 sperm competition conveyed by odours of conspecific males. Nature 431:446-449. 395 
396 Desjardins C., J. A. Maruniak, F. H. Bronson. 1973. Social rank in house mice:

397 differentiation revealed by ultraviolet visualization of urinary marking patterns.

398 Science 182:939-941.

399

400 Dufau, M. 1996. The lutenizing hormone receptor. Pp. 333-350 in A. H. Payne, M. P.

401 Hardy, and L. D. Russell, eds. The Leydig Cell. Cache River Press, Illinois.

402

403 Dzminiski, M. A., J. D. Roberts, M. Beveridge, and L. W. Simmons. 2009. Among

404 population covariation between sperm competition and ejaculate expenditure in frogs.

405 Behav. Ecol. 21:322-328.

406

407 Fuentes, L. B., N. Caravaca, L. E. Pelzer, L. A. Scardapane, R. S. Piezzi, and J. A.

408 Guzman. 1991. Seasonal variations in the testes and epididymis of vizcacha

409 (Lagostomus maximus maximus). Biol. Reprod. 45:493-497.

410

411 Firman, R. C. 2014. Female social preference for males that have evolved via

412 monogamy: evidence of a trade-off between pre- and post-copulatory sexually

413 selected traits? Biol. Lett. 10:20140659.

414

415 Firman, R. C., and L. W. Simmons. 2008. The frequency of multiple paternity

416 predicts variation in testes size among island populations of house mice. J. Evol. Biol.

$417 \quad 21: 1524-1533$.

418

419 Firman R.C., and L. W. Simmons. 2010. Experimental evolution of sperm quality via

420 postcopulatory sexual selection in house mice. Evolution 64:1245-1256. 
422 Firman, R. C., and L. W. Simmons. 2011. Experimental evolution of sperm

423 competitiveness in a mammal. BMC Evol. Biol. 11:19.

424

425 Firman, R. C., L. Y. Cheam, and L. W. Simmons. 2011. Sperm competition does not

426 influence sperm hook morphology in selection lines of house mice. J. Evol. Biol.

$427 \quad 24: 856-862$.

428

429 Firman, R. C., I. Klemme, and L. W. Simmons. 2013. Strategic adjustments in sperm

430 production within and between two island populations of house mice. Evolution

$431 \quad 67: 3061-3070$.

432

433 Gage, M. J. G. 1994. Associations between body size, mating pattern, testis size and

434 sperm lengths across butterflies. Proc. R. Soc. Lond. B. 258:247-254.

435

436 Gage, M. J. G., and E. H. Morrow. 2003. Experimental evidence of the evolution of

437 numerous, tiny sperm via sperm competition. Curr. Biol. 13:754-757.

438

439 Gier, H. T., and G. B. Marion. 1970. Development of the mammalian testis. Pp. 1-45

440 in A. D. Johnson, W. R. Gomes, and N. L. Vandemark, eds. The testis. Academic

441 Press, New York.

442

443 Goldberg, S. R., and W. S. Parker. 1975. Seasonal testicular histology of the colubrid

444 snakes, Masticophis taeniatus and Pituophis melanoleucus. Herp. 31:317-322. 
446 Gomendio, M., A. H. Harcourt, and E. R. S. Roldan. Sperm competition in mammals.

447 Pp. 667-755 in T.R. Birkhead, and A. P. Møller, eds. Sperm competition and sexual

448 selection. Academic Press, San Diego.

449

450 Harcourt, A. H., P. H. Harvey, S. G. Larson, and R. V. Short. 1981. Testis weight,

451 body weight and breeding system in the primates. Nature 293:55-57.

452

453 Harvey, S., J. Bozena, and M. Novotny. 1989. Pattern of volatile compounds in

454 dominant and subordinate male mouse urine. J. Chem. Ecol. 15:2061-2072.

455

456 Hollis, B., J. L. Fierst, and D. Houle. 2009. Sexual selection accelerates the

457 elimination of a deleterious mutant in Drosophila melanogaster. Evolution 63:324-

458333.

459

460 Hosken, D. J. 1997. Sperm competition in bats. Proc. R. Soc. Lond. B 264:385-392.

461

462 Hosken, D. J., and P. I. Ward. 2001. Experimental evidence for testis size evolution

463 via sperm competition. Ecol. Lett. 4:10-13.

464

465 Hurst, J. L. 1990. Urine marking in populations of wild house mice Mus domesticus

466 Rutty. I. Communication between males. Anim. Behav. 40:209-222.

467

468 Lüpold, S., G. M. Linz, J. W. Rivers, D. F. Westneat, and T. R. Birkhead. 2009.

469 Sperm competition selects beyond relative testes size in birds. Evolution 63:391-402. 
471 Martin, P. A., T. J. Reimers, J. R. Lodge, and P. J. Dzuik. 1974. The effect of ratios

472 and numbers of spermatozoa mixed from two males on proportions of offspring. J.

473 Reprod. Fertil. 39:251-258.

474

475 Mayhew, W. W., and S. J. Wright. 1970. Seasonal changes in testicular histology of 476 three species of the lizard genus Uma. J. Morph. 130:163-185.

477

478 McLearn, K. R., and J. T. Manning. 1985. Mate choice, monogamy and mutational 479 load. J. Theor. Biol. 116:369-376.

480

481 Montoto, L. G., M. Concepción, M. Tourmente, J. Martin-Coello, C. Crespo, J. J.

482 Luque-Larena, M. Gomendio, and E. R. S. Roldan. 2011. Sperm competition, sperm 483 numbers and sperm quality in muroid rodents. PLoS One 6:e18173.

484

485 Montoto, L. G., L. Arregui, N. M. Sanchez, M. Gomendio, and E. R. S. Roldan. 2012.

486 Postnatal testicular development in mouse species with different levels of sperm 487 competition. Reproduction 143: 333-346.

488

489 Parapanov, R., S. Nussle, J. Hausser, and P. Vogel. 2008. Relationships of basal

490 metabolic rate, relative testis size and cycle length of spermatogenesis in shrews

491 (Mammalia, Soricidae). Reprod. Fertil. Dev. 20:431-439. 
493 Parker, G. A. 1970. Sperm competition and its evolutionary consequences in the

494 insects. Biol. Rev. 45:525-567.

495

496 Parker G. A., and T. Pizzari. 2010. Sperm competition and ejaculate economics. Biol.

497 Rev. 85:897-934.

498

499 Penn, D. J., and W. K. Potts. 1998. Chemical signals and parasite-mediated sexual

500 selection. TREE 13: 391-396.

501

502 Pierce, E. J., and W. G. Breed. 2001. A comparative study of sperm production in two

503 species of Australian arid zone rodents (Pseudomys australis, Notomys alexis) with

504 marked differences in testis size. Reproduction 121:239-247.

505

506 Pitcher, T. E., P. O. Dunn, and L. A. Whittingham. 2005. Sperm competition and the

507 evolution of testis size in birds. J. Evol. Biol. 18:557-567.

508

509 Pitnick, S., G. T. Miller, J. Reagan, and B. Holland. 2001. Males' evolutionary

510 response to experimental removal of sexual selection. Proc. R. Soc. Lond. B

$511268: 1071-1080$.

512

513 Radwan, J. 2004. Effectiveness of sexual selection in removing mutations induced

514 with ionization. Ecol. Let. 7:1149-1154.

515

516 Ramm, S. A., and L. Schärer. 2014. The evolutionary ecology of testicular function:

517 size isn’t everything. Biol. Rev. doi:10.1111/brv.12084 
519 Ramm, S. A., and P. Stockley. 2009. Adaptive plasticity of mammalian sperm

520 production in response to social experience. Proc. R. Soc. Lond. B 276:745-751.

521

522 Ramm, S. A., and P. Stockley. 2010. Sperm competition and sperm length influence

523 the rate of mammalian spermatogenesis. Biol. Lett. 6:219-221.

524

525 Hochereau-de Reviers, M. H., and G. A. Lincoln. 1978. Seasonal variation in the

526 histology of the testis of the red deer, Cervus elaphus. J. Reprod. Fert. 54:209-213.

527

528 Ribble, D. O., and J. S. Millar. 1992. Intraspecific variation in testes size among

529 northern populations of Peromyscus. Funct. Ecol. 6:455-459.

530

531 Roosen-Runge, E. C. 1977. The process of spermatogenesis in mammals. Cambridge

532 University Press, Cambridge.

533

534 Rowe, M., and S. Pruett-Jones. 2011. Sperm competition selects for sperm quantity

535 and quality in the Australian Maluridae. PLoS One 6:e15720.

536

537 Russell, L. D., H. P. Ren, I. S. Hikim, W. Schulze, and A. P. S. Hikim. 1990. A

538 comparative study in twelve mammalian species of volume densities, volumes, and

539 numerical densities of selected testis components, emphasizing those related to the

540 Sertoli cell. Am. J. Anat. 188:21-30.

541

542 Sawyer, T. F. 1980. Androgen effects on responsiveness to aggression and stress- 
543 related odors of male mice. Physiol. Behav. 25:183-187.

544

545 Schärer L., P. Ladurner, and R. M. Rieger. 2004. Bigger testes do more work:

546 experimental evidence that testis size reflects testicular cell proliferation activity in

547 the marine invertebrate, the free-living flatworm Macrostomum sp. Behav. Ecol.

548 Sociobiol. 56:420-425.

549

550 SciStat Calc. 2013. Levene’s Test: equality of variances. Available at:

551 scistatcalc.blogspot.com. Accessed $2^{\text {nd }}$ November, 2014.

552

553 Shabalina, S. A., L. Y. Yampolsky, and A. S. Kondrashov. 1997. Rapid decline of

554 fitness in panmictic populations of Drosophila melanogaster maintained under

555 relaxed natural selection. Proc. Natl. Acad. Sci. USA 94:13034-13039.

556

557 Simmons, L. W. 2001. Sperm competition and its evolutionary consequences in 558 insects. Princeton University Press, Princeton.

559

560 Simmons, L. W., and F. Garcia-Gonzalez. 2008. Evolutionary reduction in testes size

561 and competitive fertilisation success in response to the experimental removal of

562 sexual selection in dung beetles. Evolution 62:2580-2591.

563

564 Stocco, D. M., and M. J. McPhaul. 2006. Physiology of testicular steroidogenesis. Pp.

565 977-1016 in J. D. Neill, T. M. Plant, D. W. Pfaff, J. R. G. Challis, D. M. De Krester,

566 Richards, J.S., and P. M. Wassarman, eds. Knobil and Neill's Physiology of

567 Reproduction. Vol. 1, Third Edition. Academic Press, Burlington. 
569 Vrech D. E., P. A. Olivero, C. I. Mattoni, and A. V. Peretti. 2014. Testes mass, but

570 not sperm length, increases with higher levels of polyandry in an ancient sex model.

$571 \quad$ PLoS ONE 9:e94135.

572

573 Whitlock, M. C., and A. F. Agrawal. 2009. Purging the genome with sexual selection:

574 reducing mutation load through selection on males. Evolution 63:569-582.

575

576 Wistuba, J., A. Schrod, B. Grieve, J. K. Hodges, H. Aslam, G. F. Weinbauer, and C.

577 M. Luetjens. 2003. Organization of seminiferous epithelium in primates: relationship

578 to spermatogenic efficiency, phylogeny, and mating system. Biol. Reprod. 69:582-

579591.

580

581 Wistuba, J. A., J. Stukenborg, and M. Luetjens. 2007. Mammalian spermatogenesis.

582 Funct. Develop. Embrol. 1:99-117.

583

584 Wolff, R. J. 1985. Mating behaviour and female choice: their relation to social status

585 in wild caught house mice Mus musculus housed in a semi-natural environment. J.

586 Zool. 207:43-51.

587

588

589

590

591

592 
593 Table 1. ANOVA comparing the proportion of sperm-producing tissue in the

594 testes of males that have evolved under either a polygamous or monogamous

595 selection regime.

596

\begin{tabular}{lrrrrr}
\hline Effect & SS & df & MS & $F$ & $P$ \\
\hline Selection history & & & & & \\
Line[selection history] & 0.034 & 1 & 0.033 & 32.602 & 0.005 \\
Error & 0.004 & 4 & 0.001 & 0.243 & 0.913 \\
& 0.223 & 54 & & &
\end{tabular}

600

601 Figure 1. The mean proportion of seminiferous tubules in the testes of house 602 mice from monogamous (3) and polygamous (3) selection lines (as measured 603 from images of histological preparations).

604

605

606

607 Figure 2. Example images displaying the difference in the density of

608 seminiferous tubules in the testes of house mice from monogamous (1-3) and 609 polygamous (4-6) selection lines. 
Figure 1.

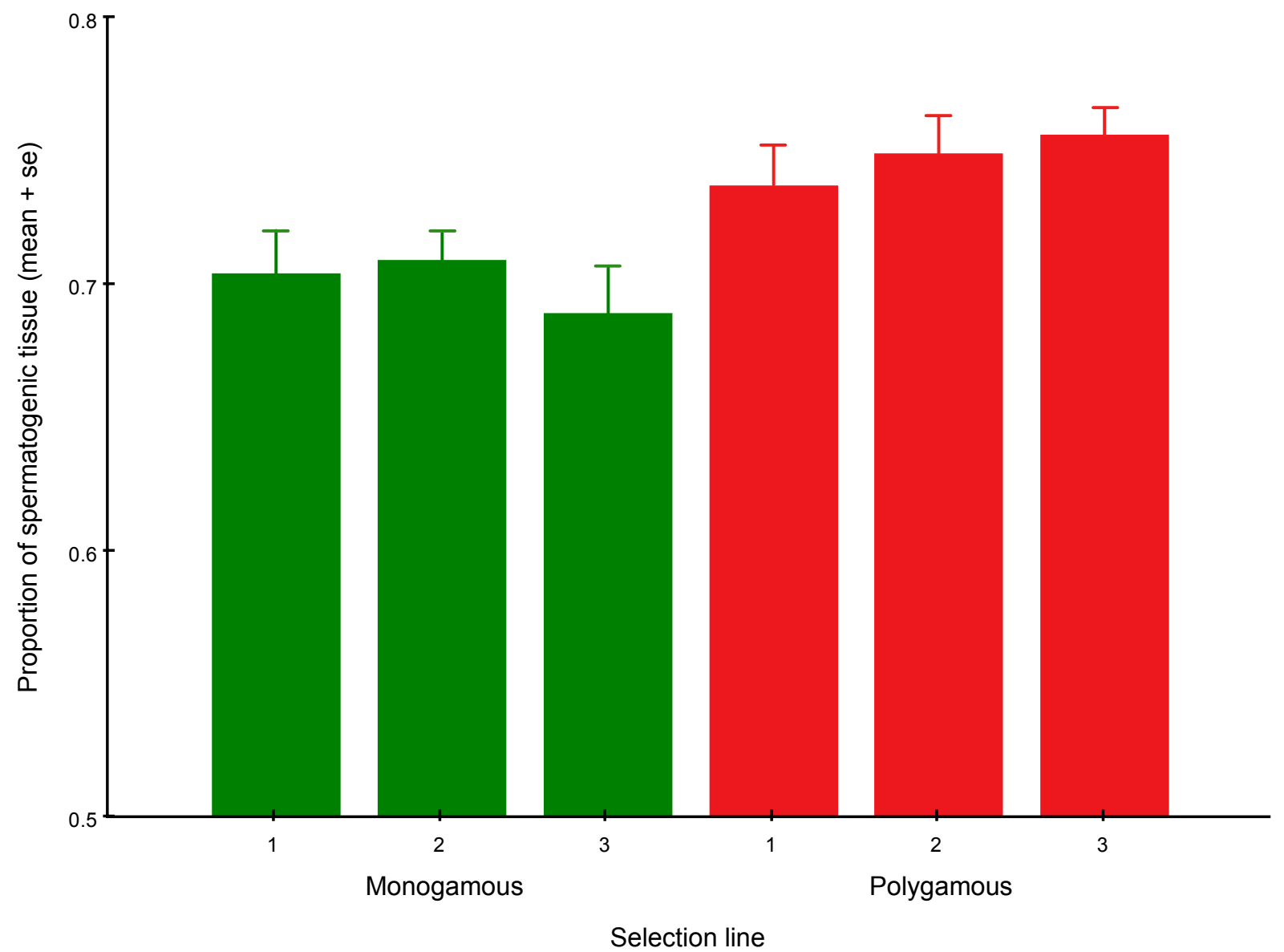




\section{Page 27 of 27}

Figure 2.
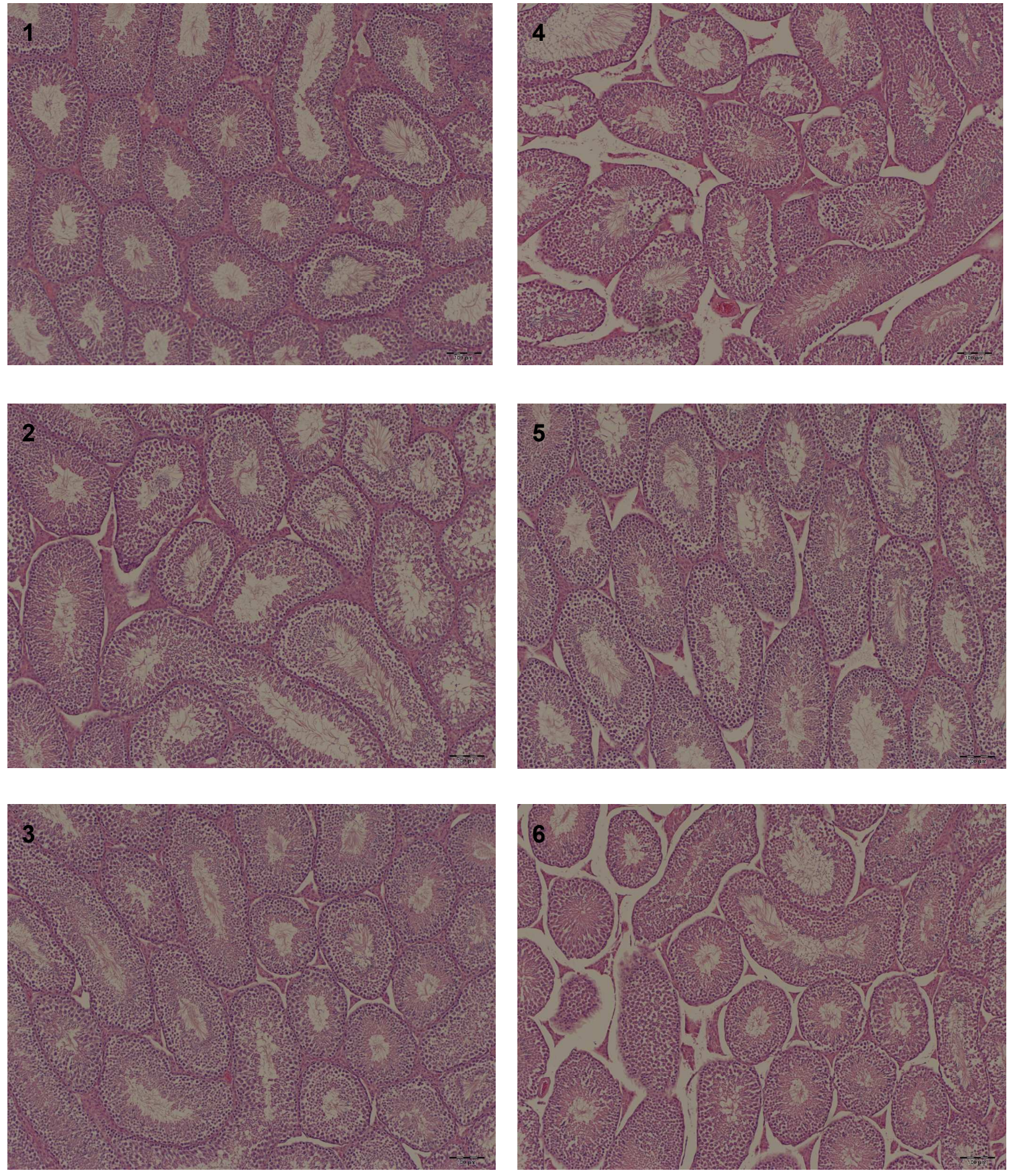